\title{
To Study the Prevalence of Chronic Respiratory Morbidities and Related Epidemiological Factors among Spinning Mill Workers
}

\author{
Saoji Ajeet (Corresponding author), Deoke Aniruddha, Kulkarni Meenal \& Nayse Jaydeep \\ Department of Community Medicine \\ NKP Salve Institute of Medical Sciences and Research Center, Nagpur \\ Tel: 982-271-5183 E-mail: ajeet.saoji@rediffmail.com \\ Mudey Abhay \\ Professor, Department of Community Medicine \\ Jawaharlal Nehru Medical College, Sawangi (M), Wardha, Maharashtra, India \\ Tel: 91-937-318-7088Ｅ-mail: abhaymudey@hotmail.com
}

\begin{abstract}
Background: Cotton and synthetic textile industry in India is the largest industry in the country accounting for 14 percent of industrial output and providing employment to around 35 million workers. The workers are at risk of suffering from various chronic respiratory illnesses like byssinosis, chronic bronchitis due to exposure to the cotton dust in the worksites. Even though quite a few studies have been conducted in textile mills in India enough emphasis has not been given on the epidemiological aspects of chronic respiratory illness among the workers in these mills. The present study was, therefore, undertaken with two fold objectives to determine prevalence of respiratory morbidities and to find out the epidemiological aspects of the respiratory morbidities in spinning mill workers.

Methodology: A Cross sectional study was conducted among 462 cotton textile workers in Babashaheb Kedar Sut Girni Pvt. Ltd. of Central India. Interview technique was used to collect sociodemographic, anthropometric $\&$ addiction information on a predesigned proforma followed by detailed general and systemic examination.

Results: Present study revealed that among 462 workers $(25.3 \%)$ workers had chronic respiratory morbidities. The morbidities included Byssinosis (11.7\%), chronic bronchitis (5.8\%), Bronchial asthma (4.5\%), Tuberculosis (1.5\%), other obstructive pulmonary diseases $(1.7 \%)$ All the workers were male and age ranged from $21-58$ years. Majority of the workers 450 i.e $(97.4 \%)$ were literate and $437(94.6 \%)$ belonged to class III \& IV according to modified Kuppu swamy's classification. The spinning process was carried out in seven main sections. Majority of the workers belonged to ring frame section 217 (47\%). The present study showed that 151 $(32.7 \%)$ had cotton dust exposure for more than 20 years. Only masks were provided as protective devices and $191(41.3 \%)$ of the workers were using it. Total $160(34.7 \%)$ workers were smokers.

Conclusion: Advancing age, sections, duration of exposure, non usage of protective devices and smoking were seen as major determinants of chronic respiratory morbidities in spinning mill workers.
\end{abstract}

Keywords: Spinning Mill worker, Smoking, Byssinosis, Chronic respiratory morbidities

\section{Introduction}

Occupational health is branch of community Medicine which deals with the effects of occupation of workplace on human health (Park. JE, 2009). Every occupation is associated with one or other ill effects on health. One such occupational group is cotton textile workers (Hunter's disease of occupation, 2000). Indian Textile Industry is one of the leading textile industries in the world and also contributes nearly $14 \%$ of the total industrial production of the country. It also contributes around 3\% to the GDP of the country. India textile industry is also the largest in the country in terms of employment generation, currently generates employment to more than 35 million people. It is also estimated that, the industry will generate 12 million new jobs by the year 2010 (India business directory, 2010). Cotton textile workers are susceptible to various respiratory morbid conditions, by virtue of workplace and working conditions and are at risk of suffering from various chronic respiratory illnesses like byssinosis, chronic bronchitis due to exposure to the cotton dust in the worksites (Hunter's disease of occupation, 2000). 
Byssinosis is an occupational lung disease often observed among workers exposed to cotton, flax, and hemp dust. Despite the fact that byssinosis has been recognized for over 100 years the etiology and pathogenesis remain obscure. The ability of textile fibres to produce byssinosis is determined by fiber type- cotton being the most potent, followed by flax, hemp and finally possible sisal. Harvested cotton consists of a mixture of plant materials including leaves, bracts and stems, fibre, bacteria, fungi and other contaminants. An important fact is that the compounds which cause byssinosis are water soluble. The biological activity of cotton can be greatly reduced by either steaming or washing the cotton before processing (David Son's Principles, 1996).

Respiratory symptoms related to cotton dust exposure may be reversible after removal from exposure with decreasing risk with increasing year since exposure cessation but can progressed to an advanced stage if exposure continues (X-R. Wang, 2005). The occurrence of respiratory symptoms represents the earliest response to cotton dust exposure, followed by lung function changes. Early respiratory symptoms may be a risk factor for subsequent loss of pulmonary function in cotton textile workers (David Son's Principles, 1996).

The severity and extent of problem are well recognized in the developed countries and control measures have been implemented to prevent the disease. This is not true, however, for the developing countries where the severity and extend of the problem are not well studied and preventive measures are far from adequate (J.R.Parikh, 1989).

Even though quite a few studies have been conducted in textile mills in India enough emphasis has not been given on the epidemiological aspects of chronic respiratory illness among the workers in these mills. The present study was, therefore, undertaken to determine prevalence of chronic respiratory morbidities and to find out the epidemiological aspects of the respiratory morbidities in spinning mill workers.

\section{Material and Methods}

A cross-sectional study was undertaken among spinning mill workers of Babasaheb Kedar Sut Girini Pvt. Ltd. Nagpur during Nov 2008 to Oct 2009. Total number of workers of this mill are 685, working in three shifts, there are seven main section involved in the spinning process wherein mixing and blowing of cotton is done in a common section. Various techniques are being used for reducing the dust concentration in the mill like Underground vacuum suction facilities is available to remove dust particles, also vacuum suction (Rider) which moves automatically from one end to another end of ring frame machine to remove dust. In mixing \& blow room there is arrangement for humidified air through special type of fan from roof corner.

In Carding, Speed Frame, Ring Frame and Winding section arrangement for cold air through humidification plant is available. Arrangement for discharge of hot air through exhaust fan is also available.

Medical facilities were not available in the premises. Neither pre employment nor periodic medical examination was available for worker. There was an allopathic dispensary, where treatment for minor ailments was available previously, but unfortunately it is also not running since last few years. Ambulance facilities are not available. In the event of occupational accident of emergency the workers are referred to E.S.I. hospital or other Govt. Hospital.

Of the total 685 workers of this mill 171 workers were not involved in the actual spinning process. Therefore these workers were excluded from the study.

Out of 514 workers who were directly involved in the spinning process 462 workers participated in the current study. The list of workers was prepared section wise. The purpose of the present study was discussed and a written permission was taken from concerned authority to carry out study. The purpose of the study and its objectives were explained to the workers. Complete history was recorded on predesigned proforma followed by detailed general and systemic examination.

\section{Standard diagnostic criteria were used for diagnosis of various morbid conditions ICD-10}

1). Byssinosis - (J66):- The Clinical Diagnosis and a grading of byssinosis was based on Roach and Schilling's Criteria-

Grade 0: No Symptoms of chest tightness or breathlessness on Mondays.

Grade $\frac{1}{2}$ : Occasional Chest tightness on Mondays or mild symptoms as irritation of the respiratory tract on Mondays.

Grade 1: Chest tightness and /or breathlessness on Mondays only.

Grade 2: Chest tightness and/or breathlessness on Mondays and other days.

Grade 3: Grade $2+$ Evidence of permanent respiratory disability from reduced ventilatory capacity. 
2). Chronic Bronchitis - (J44):- A patient is said to have chronic Bronchitis if sputum has been coughed up on most days on at least 3 consecutive months for more than 2 successive years.

3). Tuberculosis - (A15):-

A. Sputum positive symptomatic after doing sputum for AFB staining in those having -

a) Persistent cough for more than 15 days b) Continuous fever c) Chest pain

d) Hemoptysis.

B. Old TB case- All those who gave past history of TB and took treatment for it but having respiratory symptoms at the time of study.

4). Bronchial Asthma - (J45):- Either a previously diagnosed case of bronchial asthma taking treatment or those having history of paroxysms of breathlessness, chest tightness and wheezing.

5). Other Chronic Obstructive pulmonary diseases - (J44.9):- All those having respiratory symptoms for more than 15 days but the symptoms were not classical of any of the above mentioned respiratory morbid conditions.

Statistical Analysis: Data analysis was done by using Epi info software. Chi square test was used to determine the association of risk factors with chronic respiratory morbidities. Univariate analysis for risk calculation was done by odds ratio and their $95 \%$ Confidence Intervals.

\section{Results}

Present study revealed that among 462 workers $(25.3 \%)$ workers had chronic respiratory morbidities. The morbidities included Byssinosis (11.6\%), chronic bronchitis (5.8\%), Bronchial asthma (4.5\%), Tuberculosis (1.5\%), other obstructive pulmonary diseases (1.7\%). (Table-1)

Most of the workers were Hindu by religion. All the workers were male. Majority of workers $(92.2 \%)$ had average BMI and $(7.8 \%)$ were obese. The age range was from 21 to 58 years maximum number of workers (45.7\%) belonged to $40-49$ years of age group.

Majority of the workers (33.5\%) had education up to middle school and (27.3\%) up to high school. Almost (94.6\%) of the workers belonged to class III \& IV as per modified Kuppu Swamy's scale (Park. JE, 2009). The spinning process was carried out in seven main sections. Majority of the workers belonged to ring frame section (47\%). The present study showed that Average years of exposure are $15.62 \pm 6.06 \mathrm{yrs}$, wherein $(32.7 \%)$ workers had cotton dust exposure for more than 20 years. Only masks were provided as protective devices and (41.3\%) of the workers were using it. Total (34.7\%) workers were smokers and among them about $40 \%$ were found to be using 10 cigarettes/bidis per day for 20 years or more. (Table-2)

Univariate analysis of risk factors for chronic respiratory morbidities showed that Age, dusty worksites such as mixing / blow room and carding sections, duration of exposure, non usage of protective devices and smoking were found to be significantly associated. (Table-3)

\section{Discussion}

Respiratory morbidities are well known disease entity of old age. The problem becomes grave in presence of other conditions, which have an irritant effect on the lung mucosa like smoking, other indoor and outdoor pollution and incriminate worksites.

Present study revealed that among 462 workers 148 (25.3\%) workers had respiratory morbidities, Byssinosis (11.6\%), chronic bronchitis (5.8\%), Bronchial asthma (4.5\%), Tuberculosis (1.5\%), other obstructive pulmonary diseases (1.7\%). Similar study by Rajnarayan R. Tiwari et al, (2001) chronic bronchitis, upper respiratory tract infection and $1 / 2$ grade byssinosis were $4.5 \%, 7.2 \% \& 2.3 \%$ respectively, which were comparable to findings of our study.

Though cotton dust has been established as a causative agent for respiratory morbidities, it is important to determine the other risk factors associated with the occurrence of diseases so as to implement comprehensive preventive measures. So we tried to determine the association of various factors such as advancing age, lower socioeconomic status, obesity, sections, duration of exposure, non usage of protective devices and smoking.

In general, the higher age has been established as a risk factor for respiratory morbidities. A study by A.K. Mishra et al (2004) on cotton textile workers with age over 40 years was more likely to suffer from respiratory morbidities. This was quite similar to the findings of our study wherein significant association was seen between chronic respiratory morbidities and age group $>40$ years (OR-1.79). In a cotton mill, various sections are 
contaminated with different levels of cotton dust. The section of a mill in which a person works can have a definite association with the prevalence of disease, as reported by Altin et al. (2002), consistent with the findings of J P Parikh et al (1989) and Farooque et al. (2008), we found a positive association in mixing/ blow room and carding sections of the mill (OR-2.32 \& 1.59 respectively). Beside this, smoking was also found to be a significant risk factor (OR-1.75). The prevalence of chronic respiratory morbidities was $32.5 \%$ among smokers and $21.5 \%$ among non-smokers in the present study. Our finding regarding influence of smoking was very much similar to those reported by other studies $(10,13$, and 14). An association of duration of exposure with respiratory morbidities has been previously reported $(5,7)$. In the present study, we also found significant association with duration of exposure of $>20$ years (OR-2.79). Among workers using masks (17.2\%) had respiratory morbidities compared to (30.9\%) among workers not using. The difference was significant (OR-2.15). Consistent findings have been reported by other authors also $(9,12)$. In the present study lower socioeconomic status and obesity were not found to be significant risk factors.

\section{Conclusion}

It is concluded that advancing age, sections, duration of exposure, non usages of protective devices and smoking were seen as major determinants of respiratory morbidities in spinning mill workers. Efforts should be strengthened like enclosure, steaming, processing etc for reduction of dust concentration especially in mixing \& blow room and carding section. Tobacco smoking and chewing should be dissuaded and efforts should be made to improve the overall health status of spinning mill workers. Need of health education regarding use of personal protective devices such as masks and other respiratory devices. Workers having respiratory morbidities must be removed from the section of the work with high dust concentration to better assign work in other dust free sections. Pre employment and periodic examination of workers should be carried out.

\section{References}

A.K. Mishra, S.B. Rotti, A. Sahai, M. Mohan. (2004). Epidemiological study of chronic bronchitis among textile workers in Pondicherry. Indian journal of community medicine, Vol. 29, No4 (2004-10-2004-12).

Altin R, Ozkurt S, Fisekci F, Cimrin A H, Zencir M, Sevinc C. (2002). Prevalence byssinosis and respiratory symptoms among cotton mill workers. Respiration, 69: 52-56.

David Son's Principles and practice of medicine edited by Christopher RW Edwards (Churchill, living stone). (1996). 46:787-90. $17^{\text {th }}$ edition (ELBS) 321-322.

Farooque M I, Khan B, Aziz E, Moosa M, Raheel M, Kumars, Mansuri F A. (2008). Byssinosis: as seen in cotton spinning mill workers of Karachi. J Pak Med Assoc, Feb, 58(2):95-8.

Hunter's disease of occupation. (2000). Chapter - Byssinosis \& other cotton related diseases. $9^{\text {th }}$ Edition, 621-629.

India business directory. (2010). Mapsofindia.com.

International statistical classification of diseases and related health problems. (2004). ICD-10, VOL-1, Second edition, WHO, Geneva P-99,490-508.

J.R.Parikh, LJ.Bhagia, P.K.Majumdar, AR.Shah, S.K.Kashyab. (1989). Prevalence of byssinosis in textile mills at Ahmadabad, India. Br J Ind Med, 46:787-790.

Park. JE. (2009). Park. K Park's Textbook of Preventive and social medicine, Jablpur Messers Banarsideas Bhanot Publishers, $20^{\text {th }}$ edition. 318/602.

Rajnarayan R Tiwari, Mrinolini C pathak, Sanjay P. (2001). Zodpey Morbidity profile of cotton Textile workers, Vol 26 No-1 (2001-01-2001-03).

Viju T Mhase, P.S.N. Reddy. (2002). Effect of smoking on lung functions of workers exposed to dust and fumes. Indian Journal of community Medicine, Vol xxvii, No-1, Jan-Mar 2002.

Wang XR, Pan LD, Zhang HX, Sun BX, Dai HL, Christiani DC. (2002). Follow-up study of repiratory health of newly hired female cotton textile workers. Am J Ind Med., 41(2): 111-8.

X-R. Wang, H-X. Zhang, B-X. Sun, H-L Dal, J-Q. Hang, E.A. Eisen, D.H. Wegman, S.A. Olenchock and D.C. Christiani. (2005). A 20-Year follow-up study on chronic respiratory effects of exposure to cotton dust. Eur Respir J, 26; 881-886.

Yih -Ming SU1, Jenn Rong SU1, Jia-Yin SHEU1, Ching-Hui Loh and Saou-Hsing Liou. (2003). Additive effect of smoking and cotton dust exposure on respiratory symptoms and pulmonary function of cotton textile workers. Industrial health, 41, 109-115. 
Table 1. Distribution of workers according to chronic Respiratory Morbidities

\begin{tabular}{|c|c|c|c|}
\hline ICD10 & Respiratory Morbidity & $\begin{array}{c}\text { Number of } \\
\text { workers }\end{array}$ & Percentage \\
\hline J 66 & Byssinosis & $\mathbf{5 4}$ & $\mathbf{1 1 . 7} \%$ \\
\hline J 44 & Chronic Bronchitis & $\mathbf{2 7}$ & $\mathbf{5 . 8 \%}$ \\
\hline J 45 & Bronchial Asthma & $\mathbf{2 1}$ & $\mathbf{4 . 5 \%}$ \\
\hline A 15 & Tuberculosis & $\mathbf{7}$ & $\mathbf{1 . 5 \%}$ \\
\hline J 44.9 & $\begin{array}{c}\text { Other obstructive } \\
\text { Pulmonary Disease }\end{array}$ & $\mathbf{8}$ & $\mathbf{1 . 7 \%}$ \\
\hline
\end{tabular}

Table 2. Distribution of workers according to personal and Occupational characteristics

\begin{tabular}{|c|c|c|}
\hline Characteristics & Number of workers & $\%$ \\
\hline \multicolumn{3}{|l|}{ Age (in years) } \\
\hline $20-29$ & 35 & 7.6 \\
\hline 3039 & 103 & 22.3 \\
\hline $40-49$ & 211 & 45.7 \\
\hline$>50$ & 113 & 24.4 \\
\hline \multicolumn{3}{|l|}{ Obesity ( BMI ) } \\
\hline Obese $\quad(>30)$ & 36 & 7.8 \\
\hline Non-obese $(<30)$ & 426 & 92.2 \\
\hline \multicolumn{3}{|c|}{ Socioeconomic status } \\
\hline Upper/upper middle & 25 & 5.4 \\
\hline $\begin{array}{l}\text { Lower middle/upper } \\
\text { lower/lower }\end{array}$ & 437 & 94.6 \\
\hline \multicolumn{3}{|l|}{ Smoking status } \\
\hline smoker & 160 & 34.7 \\
\hline Non smoker & 302 & 65.3 \\
\hline \multicolumn{3}{|l|}{ Sections } \\
\hline Mixing/blow room & 19 & 4.1 \\
\hline Carding & 33 & 7.1 \\
\hline Ring frame & 217 & 47.0 \\
\hline Other * & 193 & 41.8 \\
\hline \multicolumn{3}{|c|}{ Duration of exposure } \\
\hline$>20$ Years & 151 & 32.7 \\
\hline$<20$ Years & 311 & 67.3 \\
\hline \multicolumn{3}{|c|}{ Safety gadgets (mask) } \\
\hline Using & 191 & 41.3 \\
\hline Not using & 271 & $\mathbf{5 8 . 7}$ \\
\hline
\end{tabular}

*Speed frame, Doubling, Reeling and winding section 
Table 3. Prevalence of respiratory morbidities with odds ratio $(95 \% \mathrm{CI})$, by different characteristics

\begin{tabular}{|c|c|c|c|c|}
\hline characteristics & Workers & $\begin{array}{c}\text { Chronic } \\
\text { Respiratory } \\
\text { morbidities\% }\end{array}$ & OR & $(95 \% \mathrm{CI})$ \\
\hline \multicolumn{5}{|l|}{ Age (in years) } \\
\hline$>40$ & 324 & 28.4 & 1.79 & $(1.09-2.94)$ * \\
\hline$<40$ & 138 & 18.1 & & \\
\hline \multicolumn{5}{|l|}{ Obesity (BMI) } \\
\hline$>30$ & 36 & 13.9 & 0.45 & $(0.17-1.19)$ \\
\hline$<30$ & 426 & 26.3 & & \\
\hline \multicolumn{5}{|l|}{ Socioeconomic status } \\
\hline $\begin{array}{l}\text { Lower middle/upper lower/ } \\
\text { lower }\end{array}$ & 437 & 25.6 & 1.37 & $(0.50-3.75)$ \\
\hline Upper/upper middle & 25 & 20 & & \\
\hline \multicolumn{5}{|l|}{ Smoking status } \\
\hline smoker & 160 & 32.5 & 1.75 & $(1.14-2.69)$ * \\
\hline Non smoker & 302 & 21.5 & & \\
\hline \multicolumn{5}{|l|}{ Sections } \\
\hline Mixing/blow room & 19 & 42.1 & 2.87 & $(1.08-7.62)$ \\
\hline Carding & 33 & 36.4 & 2.26 & $(1.02-4.97)$ \\
\hline Ring frame & 217 & 26.7 & 1.0 & $(0.9-2.28)$ \\
\hline Other ** & 193 & 20.2 & & \\
\hline \multicolumn{5}{|l|}{ Duration of exposure } \\
\hline$>20$ Years & 151 & 39.0 & 2.79 & $(1.81-4.31)$ * \\
\hline$<20$ years & 311 & 18.6 & & \\
\hline \multicolumn{5}{|l|}{ Safety gadgets (mask) } \\
\hline Not using & 271 & 30.9 & 2.15 & $(1.36-3.38)$ \\
\hline Using & 191 & 17.2 & & \\
\hline
\end{tabular}

$\mathrm{CI}=$ Confidence Interval $* *$ Speed frame, Doubling, Reeling and winding section

*Significant $\mathrm{P}<0.05$ 